\title{
A Case of Systemic Sclerosis Developed after Autologous Hematopoietic Stem Cell Transplantation in the Patient with Multiple Sclerosis
}

\author{
Woo Sin Kim, M.D. ${ }^{1}$, Chang-Ki Min, M.D. ${ }^{2,4}$, Dong Won Yang, M.D. ${ }^{3}$, \\ Yu Kyung Park, M.D. ${ }^{2}$, Son Ook Choi, M.D. ${ }^{2}$, Jin Soo Kim, M.D. ${ }^{2}$, \\ Hyeug Lee, M.D. ${ }^{2}$ and Chul-Soo Cho, M.D. ${ }^{2,5}$ \\ ${ }^{1}$ Department of Internal Medicine, Daerim Saint Mary's Hospital, ${ }^{2}$ Departments of Internal Medicine, \\ ${ }^{3}$ Neurology, ${ }^{4}$ Division of Hematology, ${ }^{5}$ Division of Rheumatology, College of Medicine, \\ The Catholic University of Korea, Seoul, Korea
}

\begin{abstract}
Herein, the case of a 43-year-old woman, with a relapsing-remitting variant of multiple sclerosis (MS), which began when she was 34 years of age, and gave rise to severe neurological complications, including progressive paralysis in both legs and visual deterioration, is reported. Despite heavy immunomodulatory treatment, her condition relapsed and became aggravated. At this point, the decision was made to perform autologous hematopoietic stem cell transplantation (HSCT). The enrichment of $\mathrm{CD} 34^{+}$cells was followed by depletion of the peripheral $\mathrm{T}$ cells. The post-transplantation course was uneventful, and autoimmune thrombocytopenia developed within 7 months of the HSCT. The patient was treated with cyclosporine (CsA) and oral prednisolone, but subsequently developed systemic sclerosis ( $\mathrm{SSc}$ ). The administration of CsA following the syngeneic/autologous HSCT caused a T lymphocyte-dependent autoimmune disease, which resembled graft-versus-host disease (GVHD). It is quite probable the auto-reactive lymphocytes, which were paradoxically elicited by the CsA during the reconstitution of the immune system, partly contributed to the occurrence of the other autoimmune disease, SSc. To our knowledge, this is the first description of a MS patient, having undergone CD34 ${ }^{+}$-selected autologous HSCT followed by the administration of CsA, who subsequently developed SSc. (Korean J Hematol 2005;40:106-110.)
\end{abstract}

Key Words: Multiple sclerosis, Systemic sclerosis, Autologous GVHD, Hematopoietic stem cell transplantation, Cyclosporine

\section{INTRODUCTION}

Recent reports suggest the possible benefits of hematopoietic stem cell transplantation (HSCT) for treating autoimmune diseases. ${ }^{1)}$ Multiple sclerosis (MS) is a serious demyelinating immune-

접수 : 2005년 4월 14일, 수정 : 2005년 5월 20일 승인 : 2005년 6월 20일

교신저자 : 민창기, 서울시 영등포구 여의도동 62 번지 (ㅇ) $150-713$, 여의도성모병원 내과 혈액분과 Tel: 02-3779-1124, Fax: 02-780-3132

E-mail:ckmin@catholic.ac.kr mediated disease of the central nervous system. There have been many unsatisfactory results reported after using conventional immunosuppressive treatments in MS patients, and MS is the most frequent disease that HSCT has been carried out among various autoimmune diseases. ${ }^{2)}$ Although the mechanisms of post-HSCT disease stabiliza-

\footnotetext{
Correspondence to : Chang-Ki Min, M.D.

Division of Hematology, Department of Internal Medicine, Saint Mary's Hospital

\#62 Yeouido-dong, Yeongdeungpo-gu, Seoul 150-713, Korea Tel: +82-2-3779-1124, Fax: +82-2-780-3132

E-mail: ckmin@catholic.ac.kr
} 
tion and improvement remain obscure, high-dose intense immunosuppressive therapy with autologous stem cell rescue has the potential to time shift the clinical autoimmune disease line to an earlier period that is analogous to the latent period, thereby restoring the self-tolerance. ${ }^{3)}$

The administration of cyclosporine (CsA) after syngeneic/autologous HSCT can bring about a type of autoimmune syndrome with a pathology almost identical to graft-versus-host disease (GVHD), which is a major complication after allogeneic HSCT and mimics many autoimmune diseases, such as scleroderma, sicca syndrome, primary biliary cirrhosis and an increased prevalence of various autoantibodies. ${ }^{4)}$

Systemic sclerosis (SSc) is a connective tissue disorder with an unknown etiology that involves many organs. ${ }^{5)}$ There are few reports of an association between MS and SSc, ${ }^{6}$ and the pathogenetic linkage of these diseases is still unknown. We report a patient with MS who underwent $\mathrm{CD} 34^{+}$selected autologous HSCT followed by the administration of CsA and then developed SSc. It is most likely that the auto-reactive lymphocytes, which were paradoxically elicited by the CsA during the reconstitution of the immune system, partly contributed to occurrence this other autoimmune disease, SSc.

\section{CASE REPORT}

We encountered a 43-year-old woman with the relapsing-remitting variant of MS with symptoms of progressive paralysis in both legs along with visual deterioration. She contracted the disease at 34 years of age. The neurological findings revealed mild, bilateral loss of position and vibration sense in the legs. The pinprick and temperature sensation tests indicated mild dysesthesia below the T2 to T4 level, with sacral sparing. She had an Expanded Disability Status Scale (EDSS) score $^{1)}$ of $6.0 \sim 6.5$. Cerebral magnetic resonance imaging $(\mathrm{MRI})($ Fig. 1) revealed multiple lesions in the basal ganglia and thalami, which were

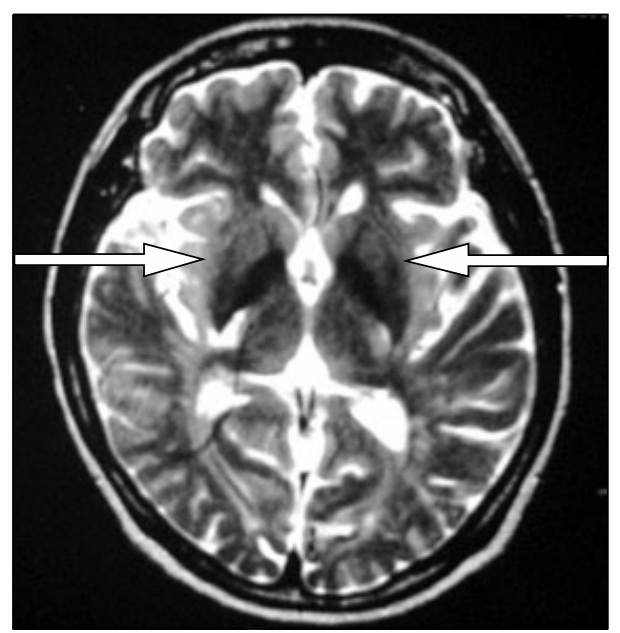

Fig. 1. Brain magnetic resonance image (MRI): An axial T2weighted image shows abnormal non-heme iron deposition in the basal ganglia and thalami.

changes consistent with demyelinization. She was treated with corticosteroids and interferon- $\beta$ However, paralysis and visual deterioration were repeated every 3 4 months. Based on the relapsing nature of her paralysis and the optical defects, which occurred despite the conventional treatments, she was considered for intense immunosuppression followed by autologous HSCT.

After extensive cross-consultation and informed consent, autologous HSCT was performed in April of 2001. In order to mobilize the hematopoietic progenitor cells into the peripheral blood, she received chemotherapy consisting of $2 \mathrm{~g} / \mathrm{m}^{2} /$ day cyclophosphamide for 2 days, followed by the administration of a granulocyte colony-stimulating factor (G-CSF) at a dose of $10 \mu \mathrm{g} / \mathrm{kg} /$ day. T-cell depletion was performed with the positive selection of $\mathrm{CD} 34^{+}$cells using the CliniMACS system (AmCell Corporation, Sunnyvale, USA), and the purified $\mathrm{CD} 34^{+}$cells were then cryopreserved in liquid nitrogen. The pretransplantation conditioning regimen was as follows: $300 \mathrm{mg} / \mathrm{m}^{2} /$ day BCNU for 1 day, $200 \mathrm{mg} / \mathrm{m}^{2} /$ day etoposide for 4days, $200 \mathrm{mg} / \mathrm{m}^{2} /$ day cytosine arabinoside for 4days, $140 \mathrm{mg} / \mathrm{m}^{2} /$ day melphalan for 1day and 1.25 $\mathrm{mg} / \mathrm{kg}$ antithymocyte globulin (ATG)(Thymoglobuline, IMTX-SangStat, France) for 3 days. After 
thawing, the total infused $\mathrm{CD} 34^{+}$cell count was $4.6 \times 10^{6} / \mathrm{kg}$. An absolute neutrophil count $>0.5 \times$ $10^{9} / \mathrm{L}$ and platelet count $>20 \times 10^{9} / \mathrm{L}$ were observed on days 12 and 15 after the HSCT, respectively. After the HSCT, her neurological deficits improved and her vision became clearer without the need for immunosuppressants. The platelet count decreased to $21 \times 10^{9} / \mathrm{L}$ in 7 months. The bone marrow findings revealed a slightly decrease in cellularity by the tissue section particles. The bone marrow pattern of the MRI was normal. She was given the high-dose intravenous immunoglobulin (IVIG) and prednisolone under the impression of idiopathic thrombocytopenia. The thrombocytopenia responded to the IVIG and steroid therapy for a short time, but further decreased within a month. The patient was treated with CsA in addition to oral prednisolone.

After 22 months of CsA administration, she had diffuse swelling of the extremities and face concomitant with Raynaud's phenomenon involving the hands and the feet. Her platelet count remained less than normal. A physical examination showed the typical appearance of scleroderma, which is tightness and atrophy of the skin of her face and hands with ulcers and irregular pigmentation on the tips of the fingers (Fig. 2). She also complained of dysphagia and mild dys- pnea. She was admitted to the department of rheumatology with worsening cutaneous and musculo-skeletal symptoms. The laboratory values obtained on a routine examination were: an erythrocyte sedimentation rate of $47 \mathrm{~mm} / \mathrm{h}$; a Creactive protein level of $3.25 \mathrm{mg} / \mathrm{dL}$; a white blood cell count of $4.0 \times 10^{9} / \mathrm{L}$ (segment neutrophil $63.8 \%$, lymphocytes $25.1 \%$ ); a hemoglobin level of $11.2 \mathrm{~g}$ / $\mathrm{dL}$; and a platelet count of $33 \times 10^{9} / \mathrm{L}$. Immunological analysis yielded the following results: $\mathrm{IgA}, 219 \mathrm{mg} / \mathrm{dL} ; \mathrm{IgG}, 2110 \mathrm{mg} / \mathrm{dL} ; \mathrm{IgM}, 151 \mathrm{mg} / \mathrm{dL}$; $\mathrm{C}^{3}, 100 \mathrm{mg} / \mathrm{dL} ; \mathrm{C}^{4}, 12.9 \mathrm{mg} / \mathrm{dL}$; the presence of anti-nuclear antibodies (a titer of $1: 640$, the fine speckled pattern), anti-RNP antibodies, and anti$\mathrm{PM} / \mathrm{Scl}$ antibodies. She exhibited sicca syndrome in her mouth and eyes. There was a positive anti-Ro (SS-A) and anti-La (SS-B) antibody count and salivary gland scintigraphy showed a decreased uptake of the radioactive tracer at the salivary system as well as delayed excretion. High resolution computed tomography (HRCT)(Fig. 3) of her chest revealed ground glass opacities in both lower lobes, suggesting fibrosis. A reduction in the single breath diffusion capacity for carbon monoxide $\left(\mathrm{DL}_{\mathrm{CO}}\right)$ is the earliest detectable functional indication of lung disease in scleroderma. ${ }^{7)}$ The pulmonary function tests revealed an impairment of the $\mathrm{DL}_{\mathrm{CO}}(68 \%$ of the predicted value) that is consistent with the interstitial lung disease. The
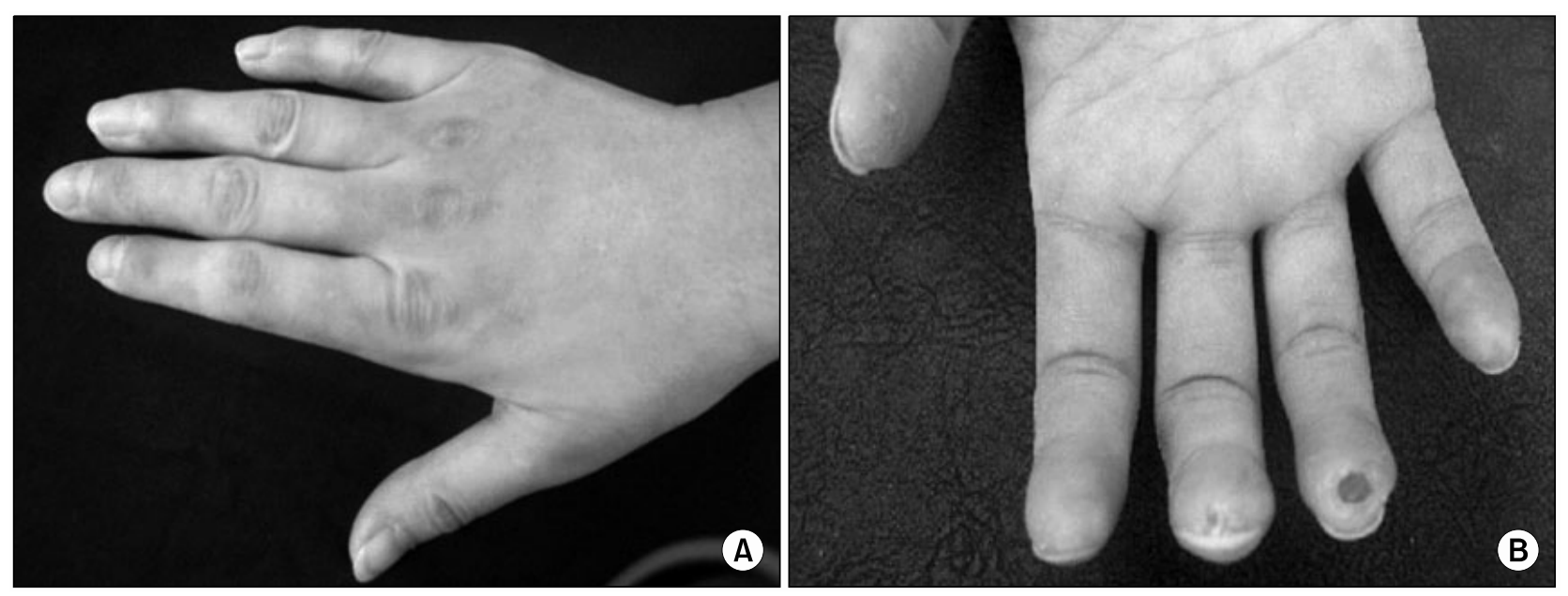

Fig. 2. (A) The hands show tightening of the skin. (B) Ulcers appear on the fingertips. 


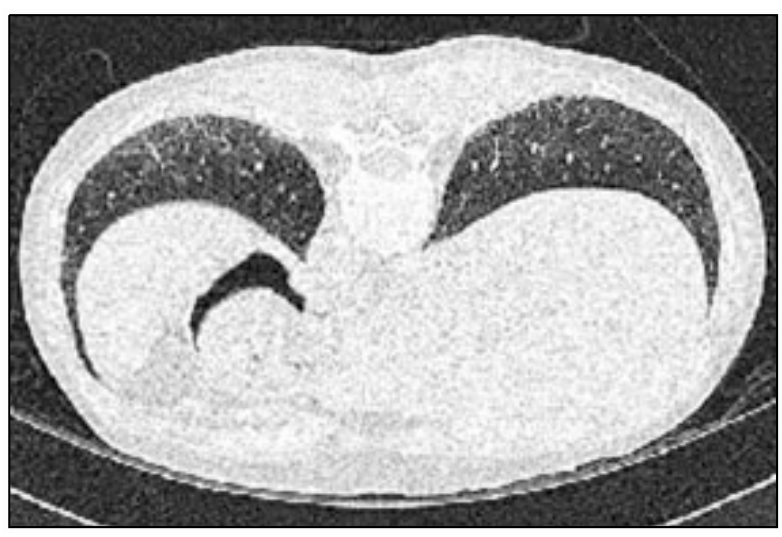

Fig. 3. Computed tomography of the chest reveals groundglass opacities in both lower lobes at prone position, suggesting fibrosis.

skin biopsies from the dorsum of the hand revealed hyperkeratosis and papillomatosis of the epidermis. The dermis was thickened due to an excess of collagen fibrils. Upper gastrointestinal endoscopy revealed reflux esophagitis. Rituximab at a dose of $375 \mathrm{mg} / \mathrm{m}^{2}$ was administered as an intravenous infusion at weekly intervals for 4 doses. Soon after the Rituximab treatment, an increase in her platelet count was observed, which remained above $100 \times 10^{9} / \mathrm{L}$. Currently, the musculo-cutaneous symptoms are improving as a result of penicillamine and steroid treatment.

\section{DISCUSSION}

We report the first case of a MS patient with who underwent a $\mathrm{CD} 34^{+}$-selected autologous HSCT followed by the long-term administration of CsA, who then developed SSc.

MS is a disease caused by the selective destruction of myelin in the central nervous system. ${ }^{8)}$ Genetic susceptibility, environmental triggers (possibly viral), and abnormal immunological reactions lead to focal myelin destruction as well as secondary damage to the axons. ${ }^{8)}$ The standard treatment modalities for MS include immunosuppression with steroids and/or cytotoxic drugs, and immunomodulation with either interferon- $\beta$ or glatiramer acetate. ${ }^{9)}$ Unfortunately, the treat- ments available are not curative. Based on experimental data, a HSCT has been suggested for the treatment of severe and refractory $\mathrm{MS} .{ }^{10)}$ The rationale for HSCT in treating MS is based on the principle of complete ablation of an aberrant immune system followed by the reconstitution of a new immune system derived from either a T cell-depleted autologous transplant or an allogeneic donor. ${ }^{8)}$

Based on the relapsing nature of her paralysis and the optical defects, which occurred despite the conventional immunosuppressive treatments, the patient received an autologous HSCT. The Tcell-depleted $\mathrm{CD}_{3}{ }^{+}$cell transplantation was performed using an immunomagnetic device. During the follow-up, the patient developed thrombocytopenia that was controlled with CsA and oral prednisolone.

CsA is an effective immunosuppressive agent that apparently has selective action on the $\mathrm{T}$ lymphocyte-dependent immune responses. ${ }^{11)}$ Despite its potent immunosuppressive activity, the administration of CsA after an autologous/syngeneic HSCT ironically elicits a $\mathrm{T}$ lymphocytedependent autoaggression syndrome known as autologous/syngeneic GVHD. ${ }^{12)}$ The induction of autologous/syngeneic GVHD requires two essential components, the emergence of autoreactive lymphocytes from the thymus and the elimination of a $\mathrm{T}$ cell-dependent peripheral autoregulatory mechanism. ${ }^{12)}$ The effects of CsA are important in preventing the re-establishment of regulatory cells and in allowing the development of autoreactive cells. $^{13)}$ In our patient, the use of CsA following autologous HSCT might be associated with the development of SSc as part of the complex immune response involved in autologous GVHD. It is quite possible that the auto-reactive lymphocytes, which were elicited by the CsA during the reconstitution of immune system, partly contributed to occurrence of another autoimmune disease, SSc. SSc is an autoimmune disorder with an unknown etiology. It is characterized by severe and progressive cutaneous and visceral fibrosis, 
pronounced alterations in the microvasculature, and numerous cellular and humoral immunological abnormalities. ${ }^{5)}$ It has become clear that the activated cellular-immune system plays a key role in the pathogenesis of SSc. ${ }^{14)}$

In summary, to our knowledge this is the first report of a MS patient who developed SSc following autologous HSCT and subsequent CsA administration. During the reconstitution of immune system following T-cell depleted autologous HSCT, CsA administration may induce aberrant autoreactive $\mathrm{T}$ cells although the underlying mechanisms are not determined. Therefore, a high degree of caution should be advised when CsA is administered to patients receiving autologous HSCT.

\section{REFERENCES}

1) Gratwohl A, Passweg J, Gerber I, Tyndall A. Stem cell transplantation for autoimmune diseases. Best Pract Res Clin Haematol 2001;14:755-76.

2) Fassas A, Passweg JR, Anagnostopoulos A, et al. Hematopoietic stem cell transplantation for multiple sclerosis: a retrospective multicenter study. J Neurol 2002;249:1088-97.

3) Hashimoto N, Iwasaki T, Sekiguchi M, et al. Autologous hematopoietic stem cell transplantation for refractory antiphospholipid syndrome causing myocardial necrosis. Bone Marrow Transplant 2004;33: 863-6.

4) Vinzio S, Lioure B, Grunenberger F, Schlienger JL, Goichot B. Auto-immune-like disease post-bone marrow transplantation. Rev Med Interne 2004;25:514-23.

5) Artlett CM. Immunology of systemic sclerosis. Front Biosci 2005;10:1707-19.

6) Spadaro A, Sensi F, Barrella M, Francia A. Systemic sclerosis and multiple sclerosis. J Neurol 1999;246: 497-9.

7) Kikuchi K, Igarashi A, Ishibashi Y, Inokuma S, Takehara K. The correlations of respiratory function tests, chest roentgenographic manifestations and respiratory symptoms in the patients with systemic sclerosis, using a scoring-method for symptoms. Nippon Hifuka Gakkai Zasshi 1990;100:695-700.

8) Fassas A, Anagnostopoulos A, Kazis A, et al. Peripheral blood stem cell transplantation in the treatment of progressive multiple sclerosis: first results of a pilot study. Bone Marrow Transplantation 1997;20: 631-8.

9) Noseworthy JH, Lucchinetti C, Rodriguez M, Weinshenker BG. Multiple sclerosis. N Engl J Med 2000; 343:938-52.

10) Fassas A, Kimiskidis VK. Stem cell transplantation for multiple sclerosis: What is the evidence? Blood Reviews 2003;17:233-40.

11) Hess AD, Horwitz LR, Laulis MK, Fuchs E. Cyclosporine-induced syngeneic graft-vs-host disease: prevention of autoaggression by treatment with monoclonal antibodies to T lymphocyte cell surface determinants and to MHC class II antigens. Clin Immunol Immunopathol 1993;69:341-50.

12) Hess AD, Fischer AC, Horwitz L, Bright EC, Laulis MK. Characterization of peripheral autoregulatory mechanisms that prevent development of cyclosporininduced syngeneic graft-versus-host disease. J Immunol 1994;153:400-11.

13) Fischer AC, Laulis MK, Horwitz L, Beschorner WE, Hess AD. Host resistance to cyclosporine induced syngeneic graft-versus-host disease. Requirement for two distinct lymphocyte subsets. J Immunol 1989; 143:827-32.

14) Ercole LP, Malvezzi M, Boaretti AC, Utiyama SR, Rachid A. Analysis of lymphocyte subpopulations in systemic sclerosis. J Investig Allergol Clin Immunol 2003;13:87-93. 